\title{
Insulin-like growth factor-1 promotes the proliferation and odontoblastic differentiation of human dental pulp cells under high glucose conditions
}

\author{
LU YAN ${ }^{1}$, SHANGMIN SUN ${ }^{2}$ and LIU QU ${ }^{1}$ \\ Departments of ${ }^{1}$ Endodontics and ${ }^{2}$ Periodontics, School of Stomatology, \\ China Medical University, Shenyang, Liaoning 110002, P.R. China
}

Received January 27, 2016; Accepted August 7, 2017

DOI: $10.3892 / \mathrm{ijmm} .2017 .3117$

\begin{abstract}
Insulin-like growth factor-1 (IGF-1) promotes human dental pulp stem cell proliferation and osteogenic differentiation. However, the effects of IGF-1 on the proliferation, apoptosis and odontoblastic differentiation (mineralization) of dental pulp cells (DPCs) under high glucose (GLU) conditions remain unclear. In this study, isolated primary human DPCs were treated with various concentrations of high GLU. Cell proliferation and apoptosis were determined by Cell Counting Kit- 8 and Annexin V-FITC/PI assays, respectively. The cells were cultured in odontoblastic induction medium containing various concentrations of high GLU. Odontoblastic differentiation was determined by alkaline phosphatase (ALP) activity assay. Mineralization formation was evaluated by von Kossa staining. The expression levels of IGF family members were measured by western blot analysis and RT-qPCR during proliferation and differentiation. The cells were then exposed to $25 \mathrm{mM}$ GLU and various concentrations of IGF-1. Cell proliferation, apoptosis, ALP activity, mineralization formation and the levels of mineralization-related proteins were then evaluated. Our results revealed that high GLU significantly inhibited cell proliferation and promoted cell apoptosis. GLU ( 25 and $50 \mathrm{mM}$ ) markedly reduced ALP activity and mineralization on days 7 and 14 after differentiation. The levels of IGF family members were markedly decreased by high GLU during proliferation and differentiation. However, IGF-1 significantly reversed the effects of high GLU on cell proliferation and apoptosis. Additionally, IGF-1 markedly restored the reduction of ALP activity and mineralization induced by high GLU. Our findings thus indicate that IGF-1 attenuates the high GLU-induced inhibition of DPC proliferation, differentiation and mineralization.
\end{abstract}

Correspondence to: Dr Lu Yan, Department of Endodontics, School of Stomatology, China Medical University, 117 North Nanjing Street, Shenyang, Liaoning 110001, P.R. China

E-mail: lu_yan2009@yeah.net

Key words: high glucose, dental pulp cells, proliferation, apoptosis, odontoblastic differentiation, insulin-like growth factor 1

\section{Introduction}

Dental pulp participates in the reparative regeneration of the tooth tissues (1). Dental pulp tissue contains multiple cells that possess plasticity and multipotency, including fibroblasts, inflammatory and immune cells, odontoblasts and undifferentiated mesenchymal cells (1-3). Fibroblasts and odontoblasts are the main cell types in dental pulp (4). In response to stimuli or injuries, dental pulp cells (DPCs) differentiate into odontoblasts to replace the necrotic cells and then generate reparative dentin (5).

Diabetes mellitus (DM) is a severe chronic disease that markedly affects the health and life quality of individuals (6). DM is a multi-organ and multi-factorial metabolic disease that is characterized by absolute or relative deficiency in insulin secretion, insulin resistance and $\beta$-cell dysfunction, which may ultimately lead to hyperglycemia (7-9). DM is a major cause of morbidity and mortality worldwide (10). Approximately 87 million adults suffered from the disease in 2014. The number of individuals with DM is expected to increase to almost 592 million by the year 2035 (11). DM may lead to numerous complications, including cardiovascular diseases, microvascular diseases (such as diabetic retinopathy), osteoporosis and diabetic nephropathy $(12,13)$. Additionally, DM also affects the functions of dental pulp and periapical tissues $(14,15)$. A previous study indicated that DM can result in the necrosis of dental pulp and in the development of periapical lesions in diabetic rats (16). Long-term DM has been demonstrated to increase the basement membranes thickness of dental pulp vessels and to contribute to the occurrence and development of angiopathy (17). It also been demonstrated that rats with streptozotocin (STZ)-induced diabetes exhibit a significant reduction in pulpal blood flow (18). Moreover, hyperglycemia inhibits dentin bridge formation and enhances inflammatory cell infiltration in diabetic rats (19).

Insulin-like growth factor-1 (IGF-1), a member of the insulin-like peptide family, plays a vital role in the survival, apoptosis and differentiation of cells within various organs, including teeth (20-22). Joseph et al found that secretory ameloblasts, secretory odontoblasts and mature ameloblasts express high levels of IGF-1 in the development of the rat incisor (23). It has also been demonstrated that IGF-1 promotes human dental pulp stem cell proliferation and osteogenic differentiation by 
increasing the expression of differentiation markers through the mammalian target of rapamycin (mTOR) signaling pathway (24). IGF-1 has also been reported to protect DPCs against the cytotoxicity of composite materials via endogenous antioxidant mechanisms (25).

In the present study, we cultured primary human DPCs in order to investigate the effects of high glucose (GLU) on the proliferation, apoptosis and differentiation/mineralization of DPCs. We further evaluated the protective effects of IGF-1 under high GLU conditions. Our study provides insight into possible treatment options to counteract the oral complications associated with DM.

\section{Materials and methods}

Isolation of human DPCs. Human premolars extracted for orthodontic purposes and third molars from patients without dental carious and periodontal problems (a total of 80 adults; age: 18-25 years old) were obtained from China Medical University School and Hospital of Stomatology. Dental pulp tissues were obtained from teeth and washed with phosphatebuffered saline (PBS). All study protocols were approved by the Ethics Committee of China Medical University. Written informed consent was written from all patients. The tissues were then cut into sections and digested with $0.3 \%$ type I collagenase and $0.4 \%$ dispase at $37^{\circ} \mathrm{C}$ for $1 \mathrm{~h}$. The isolated human DPCs were cultured in Dulbecco's modified Eagle's medium (DMEM) (Gibco, Grand Island, NY, USA) supplemented with $10 \%$ fetal bovine serum (FBS) (HyClone Laboratories, Inc., Logan, UT, USA) at $37^{\circ} \mathrm{C}$ in a $5 \% \mathrm{CO}_{2}$ atmosphere.

Odontoblastic differentiation. The cells at passage 3 were seeded on culture dishes. After being grown to $70-80 \%$ confluence, the cells were cultured in odontoblastic induction medium (OM) for 1, 3, 7 and 14 days, composed of DMEM, $50 \mu \mathrm{g} / \mathrm{ml}$ ascorbic acid and $10 \mathrm{mM} \beta$-glycerophosphate sodium (both from Sigma-Aldrich, St. Louis, MO, USA).

Cell proliferation assay. The DPCs were seeded into 96-well plates at a density of $2 \times 10^{3}$ cells/well and cultured in DMEM containing various concentrations of GLU (10, 25 and $50 \mathrm{mM}$ ) (Sigma-Aldrich). The cells were cultured for 24, 48 and 72 h. Cell Counting Kit-8 (CCK-8) agent (10 $\mu \mathrm{l})$ (Beyotime Institute of Biotechnology, Inc., Haimen, China) was then added to each well and the cells were incubated for $1 \mathrm{~h}$ at $37^{\circ} \mathrm{C}$. The absorbance was measured at $450 \mathrm{~nm}$ using a microplate reader (ELX-800; BioTek Instruments, Inc., Winooski, VT, USA). The optimum concentration of GLU was determined.

In addition, the cells were plated in 96-well plates $\left(2 \times 10^{3}\right.$ cells/well) and maintained in DMEM containing high GLU (25 mM). The dose of GLU $(25 \mathrm{mM})$ used was the minimum effective dose. The cells were then treated with various concentrations of IGF-1 (10, 50 and $100 \mathrm{ng} / \mathrm{ml})$ for 24 , 48 and 72 h (Peprotech Inc., Rocky Hill, NJ, USA). Cell proliferation was evaluated by CCK-8 assay (Beyotime Institute of Biotechnology, Inc.) according to the manufacturer's instructions.

Cell apoptosis assay. The cells were harvested after the corresponding treatments and washed twice with PBS.
Following centrifugation at $800 \mathrm{rpm}$ for $5 \mathrm{~min}$, the cells were resuspended in $500 \mu \mathrm{l}$ binding buffer gently. Subsequently, $5 \mu \mathrm{l}$ Annexin V-FITC and $5 \mu \mathrm{l}$ propidium iodide (PI) (KeyGen Biotech Co., Nanjing, China) were added to the suspension and mixed immediately. The cell suspension was incubated at room temperature for $15 \mathrm{~min}$ in the dark and analyzed by flow cytometry (Model C6; BD Biosciences, San Jose, CA, USA).

Alkaline phosphatase (ALP) activity assay. The cells were resuspended in $100 \mu \mathrm{l}$ PBS and subjected to repeated freeze-thawing cycles. The supernatant was obtained by centrifugation at $12,000 \mathrm{rpm}$ for $10 \mathrm{~min}$ and quantified by BCA (Wanleibio, Shenyang, China). The activity of ALP was measured using an ALP assay kit (Nanjing Jiancheng Bioengineering Institute, Nanjing, China) according to the manufacturer's instructions and expressed as $\mathrm{U} / \mathrm{g}$ protein.

von Kossa staining. The fixed cells were washed 3 times with deionized water. Subsequently, the cells were stained with $1 \%$ silver nitrate (Jizhun, Shanghai, China) and exposed to ultraviolet light for $20 \mathrm{~min}$. After washing with deionized water, the cells were incubated for 5 min with $5 \%$ sodium thiosulfate and counterstained for $30 \mathrm{sec}$ with $0.1 \%$ nuclear fast red (both from Sinopharm Chemical Reagent Co., Ltd., Beijing, China). The coverslips were dehydrated in ethanol (75, 85, 95 and 100\%) and captured under a microscope (DP73; Olympus, Tokyo, Japan).

Western blot analysis. Total proteins were extracted from the cells using the total protein extraction kit purchased from Wanleibio and quantified. Total proteins (40 $\mu \mathrm{g}$ in each lane) were subjected to 8,10 or $15 \%$ SDS-PAGE (Wanleibio), followed by transfer onto PVDF membranes (EMD Millipore, Bedford, MA, USA). The membranes were blocked with non-fat milk and then incubated at $4^{\circ} \mathrm{C}$ overnight with antibodies against osteocalcin (OCN) (1:200; sc-376835), osteonectin (ON) (1:200; sc-398419), dentin matrix protein-1 (DMP-1) (1:200; sc-73633) (all from Santa Cruz Biotechnology, Inc., Santa Cruz, CA, USA), osteopontin (OPN) (1:500; D121078; Sangon Biotech Co., Ltd., Shanghai, China), dentin sialoprotein (DSP) (1:500; bs-8557R; BIOSS, Beijing, China), IGF-1 (1:400; BA0939), IGF-1 receptor (IGF-1R) (1:400; BA0498), IGF-binding protein 1 (IGFBP1) (1:400; BA1749) and IGFBP3 (1:400; BA3641) (all from Boster Biological Technology, Ltd., Wuhan, China). The membranes were washed and incubated at $37^{\circ} \mathrm{C}$ for $45 \mathrm{~min}$ with goat anti-rabbit/mouse horseradish peroxidase (HRP)-conjugated secondary antibody $(1: 5,000$; WLA023/WLA024; Wanleibio). The protein bands were visualized by using enhanced chemiluminescence (ECL) substrate (Wanleibio) and quantified using Gel-Pro Analyzer 4.0 (Media Cybernetics, Inc., Rockville, MD, USA).

Reverse transcription-quantitative polymerase chain reaction $(R T-q P C R)$. Total RNA was extracted using the RNApure total RNA extraction kit (BioTeke Corp., Beijing, China) and $1 \mu \mathrm{g}$ total RNA was reverse transcribed into cDNA using M-MLV reverse transcriptase ((BioTeke Corp.) according to the manufacturer's instructions. The primers used in this study were synthesized by Sangon Biotech Co., Ltd. and were as follows: IGF-1 forward, 5'-ACAAGCCCACAGGGTATG-3' 

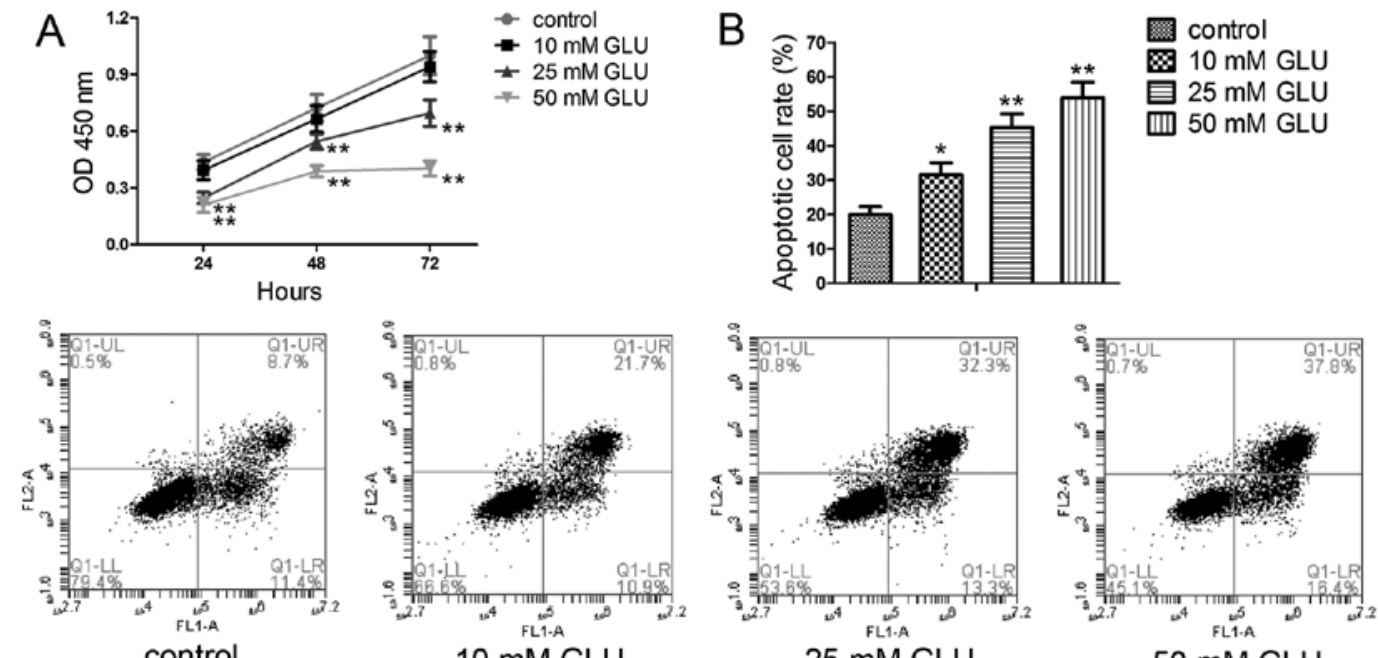

$25 \mathrm{mM}$ GLU

$50 \mathrm{mM}$ GLU

Figure 1. Effect of high glucose (GLU) on the proliferation and apoptosis of human dental pulp cells (DPCs). (A) The proliferative ability of DPCs was determined by Cell Counting Kit-8 (CCK-8) assay at 24, 48 and $72 \mathrm{~h}$ following exposure to high GLU (10, 25 and $50 \mathrm{mM}$ ). (B) Cell apoptosis was measured by Annexin V-FITC/propidium iodide (PI) staining assay. ${ }^{*} \mathrm{P}<0.05$ and $^{* *} \mathrm{P}<0.01$ vs. control group.

and IGF-1 reverse, 5'-CACTCCCTCTACTTGCGTTCT-3'; IGF-1R forward, 5'-TGCTGTATGCCTCTGTGAACC-3' and IGF-1R reverse, 5'-AGACCATCCCAAACGACCC-3'; IGFBP1 forward, 5'-CCTGCCAAACTGCAACAAG-3' and IGFBP1 reverse, 5'-CCCATTCCAAGGGTAGACG-3'; IGFBP3 forward, 5'-TAAGGTGGAGTCCTACTTGTTT-3' and IGFBP3 reverse, 5'-ACTTGTGATGCCTCTGAATG-3'; and $\beta$-actin forward, 5'-CTTAGTTGCGTTACACCCTTTC TTG-3' and $\beta$-actin reverse, 5'-CTGTCACCTTCACCGT TCCAGTTT-3'. qPCR amplification $\left(95^{\circ} \mathrm{C}\right.$ for $10 \mathrm{~min}$, followed by 40 cycles of $95^{\circ} \mathrm{C}$ for $10 \mathrm{sec}, 60^{\circ} \mathrm{C}$ for $20 \mathrm{sec}$ and $72^{\circ} \mathrm{C}$ for $30 \mathrm{sec}$ ) was performed on an Exicycler ${ }^{\mathrm{TM}} 96$ quantitative fluorescence analyzer (Bioneer Co., Daejeon, Korea) using SYBR-Green (Solarbio, Beijing, China). Gene expression levels were normalized to $\beta$-actin levels and calculated using $2^{-\Delta \Delta \mathrm{Ct}}$ method (26).

Statistical analysis. Data are expressed as the meand \pm SD. All data were analyzed by one-way analysis of variance (ANOVA) and Bonferroni's multiple comparison test. A P-value $<0.05$ was considered to indicate a statistically significant difference.

\section{Results}

High GLU inhibits the proliferation and promotes the apoptosis of human DPCs. In this study, CCK-8 assay was performed to evaluate the effects of high GLU on the proliferation of DPCs. As shown in Fig. 1A, exposure to high GLU (at concentrations of 25 and $50 \mathrm{mM}$ ) for 24,48 and $72 \mathrm{~h}$ significantly decreased the viability of the DPCs compared with the control group. The effects of high GLU on cell apoptosis were also investigated by Annexin V-FITC/PI staining. As shown in Fig. 1B, exposure to GLU (10,25 and $50 \mathrm{mM}$ ) markedly promoted the apoptosis of the DPCs compared with the control group, as evidenced by the increased apoptotic rate.

High GLU inhibits the odontoblastic differentiation of and mineralization in DPCs. No statistically significant differ- ences were observed in the activity of ALP among the groups on days 1 and 3 (Fig. 2A). ALP activity in the cells cultured in OM was significantly higher than that of the untreated control cells on days 7 and 14. Exposure to hight GLU (25 and $50 \mathrm{mM}$ ) significantly reduced this increase from day 7 after differentiation. Mineralization in DPCs was assessed by von Kossa staining. Our data indicated that mineralized matrix formation in the cells cultured in OM was markedly enhanced compared with the control group on days 7 and 14 (Fig. 2B). However, exposure to high GLU (25 and $50 \mathrm{mM}$ ) significantly inhibited odontoblastic mineralization.

High GLU reduces the expression levels of IGF family members in DPCs. A previous study reported that IGF-1 can promote the proliferation and osteogenic differentiation of human dental pulp stem cells (24). Therefore, we examined the expression levels of several IGF family members in the DPCs after the indicated treatments. The cells were cultured in normal DMEM and exposed to increasing concentrations of GLU for $24 \mathrm{~h}$. Compared with the control group, there was a significant reduction in the IGF-1, IGF-1R, IGFBP1 and IGFBP3 protein levels in the GLU-exposed cells (Fig. 3A). Consistent with the results of western blot analysis, the corresponding decreases were confirmed by RT-qPCR (Fig. 3B).

Furthermore, the cells were maintained in differentiation medium. After 7 days of differentiation, the mRNA and protein levels of IGF-1, IGF-1R, IGFBP1 and IGFBP3 in the OM + GLU groups were markedly decreased in comparison with the $\mathrm{OM}$ group, as evaluated by western blot analysis (Fig. 3C) and RT-qPCR (Fig. 3D). Several days after differentiation, the protein levels of IGF-1 (days 7 and 14), IGF-1R (days 3, 7 and 14), IGFBP1 (days 7 and 14) and IGFBP3 (days 7 and 14) in the $\mathrm{OM}+25 \mathrm{mM}$ GLU group were significantly lower than those in the OM group (Fig. 3E). Markedly decreased mRNA levels were firstly observed on day 3 (Fig. 3F).

IGF-1 abolishes the effect of high GLU on the proliferation and apoptosis of DPCs. The cells were then exposed to $25 \mathrm{mM}$ 

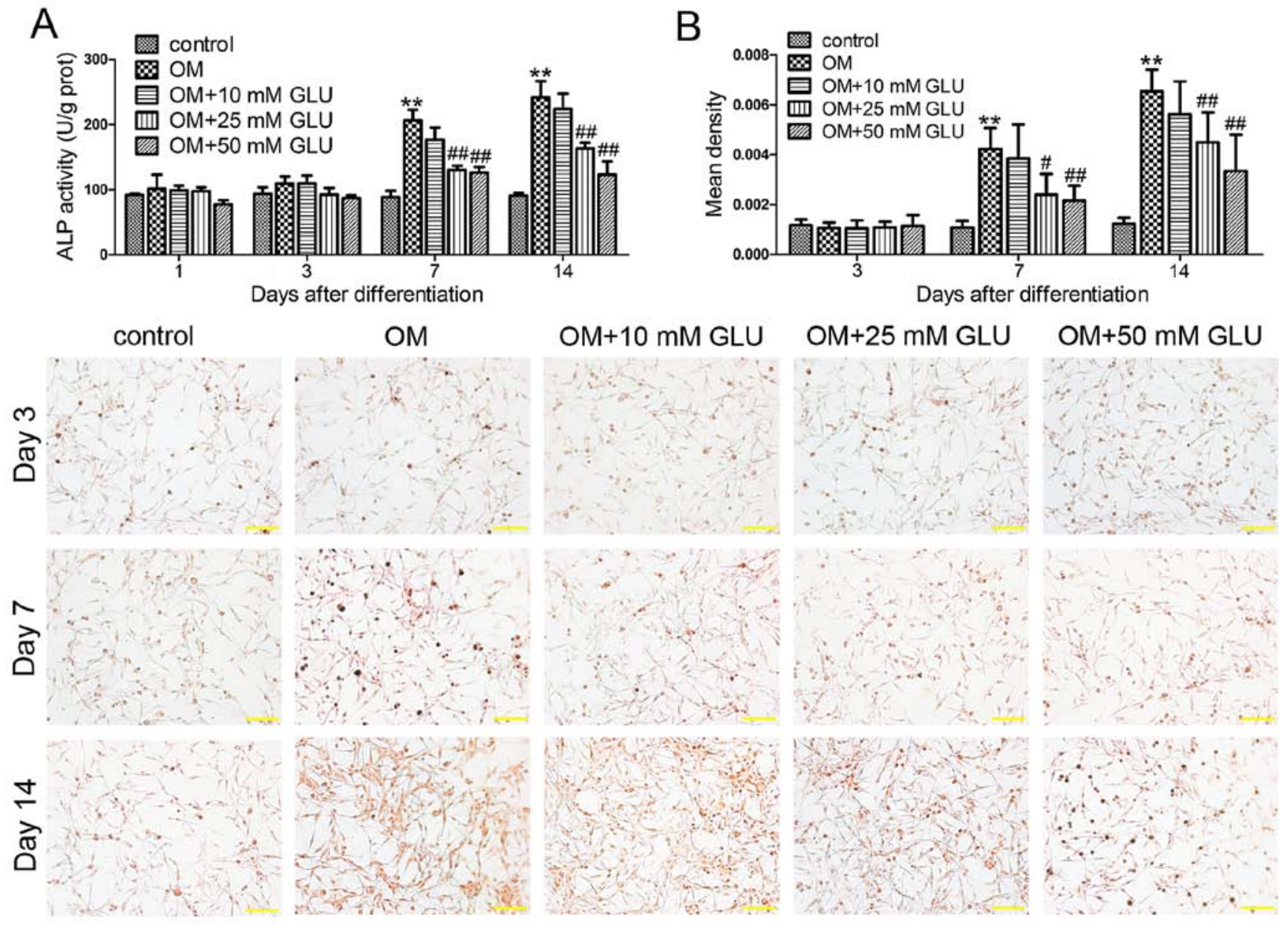

Figure 2. Effect of high glucose (GLU) on the differentiation and mineralization of dental pulp cells (DPCs). (A) The cells were cultured with odontoblastic induction medium (OM) containing high GLU. Alkaline phosphatase (ALP) activity was measured on days 1, 3, 7 and 14 after differentiation. (B) The mineralized nodules in the cells were evaluated by von Kossa staining on days 3, 7 and 14 after differentiation induction. Scale bar, $200 \mu \mathrm{m} .{ }^{* *} \mathrm{P}<0.01$ vs. control group; ${ }^{\#} \mathrm{P}<0.05$ and ${ }^{\# \#} \mathrm{P}<0.01$ vs. OM group.

GLU and various concentrations of IGF-1. As shown in Fig. 4A, in the presence of IGF-1 at concentrations of 50 and $100 \mathrm{ng} /$ $\mathrm{ml}$, cell viability was significantly increased compared with the $25 \mathrm{mM}$ GLU group. As expected, the pro-apoptotic effects of high GLU were markedly suppressed by treatment with $100 \mathrm{ng} /$ ml IGF-1 (Fig. 4B).

IGF-1 attenuates the effect of high GLU on the odontoblastic differentiation of and mineralization in DPCs. Subsquently, the cells were cultured for different periods of time in OM with $25 \mathrm{mM}$ GLU and IGF-1. The results demonstrated that the inhibitory effects of high GLU on ALP activity (Fig. 5A) were markedly abolished by IGF-1 (50 and $100 \mathrm{ng} / \mathrm{ml}$ ) on day 7 after odontoblastic induction. Treatment with various concentrations of IGF-1 reversed the effects of high GLU on mineralization in DPCs. However, the difference was not statistically significant (Fig. 5B).

IGF-1 restores the decreased levels of mineralizationrelated proteins induced by high GLU. Furthermore, western blot analysis was used to measure the expression levels of mineralization-related proteins. Our results revealed that the OCN, ON, OPN, DSP and DMP-1 levels in the OM group were significantly higher than those in the control group (Fig. 6). In the presence of $25 \mathrm{mM} \mathrm{GLU}$, the levels of these mineralizationrelated proteins in the OM $+25 \mathrm{mM} \mathrm{GLU}$ group were markedly decreased compared with the OM group. However, IGF-1 treatment significantly restored the high GLU-induced decrease in the levels of mineralization-related proteins, including OCN, ON, OPN, DSP and DMP-1.

\section{Discussion}

The process of dentinal regeneration involves the proliferation and differentiation of DPCs into odontoblasts, dental pulp healing and reparative dentin formation (27). A high sucrose diet affects the dentin-pulp complex and reduces dentin formation, which contributes to caries in dentin (28). The effect of high GLU on the proliferation, apoptosis and differentiation of DPCs warrants further investigation. In the present study, we demonstrated that high GLU suppressed the proliferation, induced the apoptosis and inhibited the differentiation of human DPCs, accompanied by reduced levels of IGF-1 family members, including IGF-1, IGF-1R, IGFBP1 and IGFBP3. We then evaluated the effects of IGF-1 on the biological properties of DPCs under high GLU conditions. We found that IGF-1 treatment reversed the effects of high GLU on DPCs. 
A

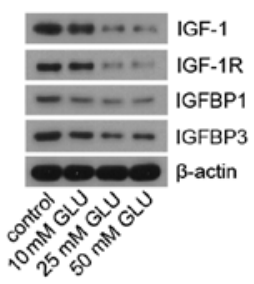

C
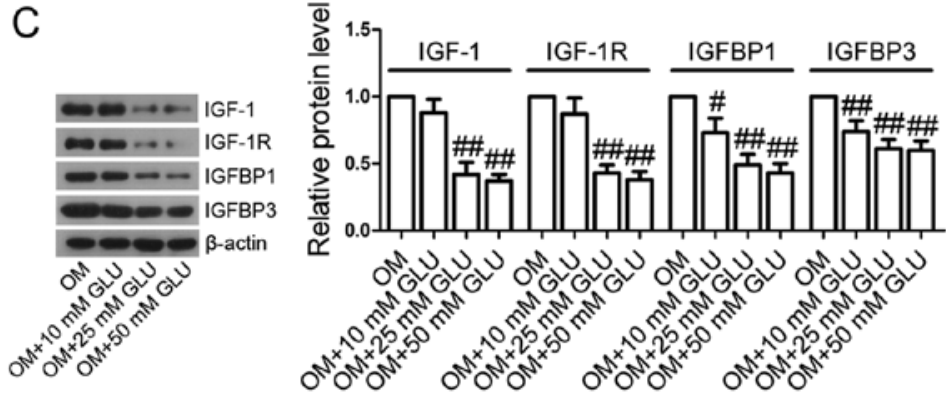

IGF-1
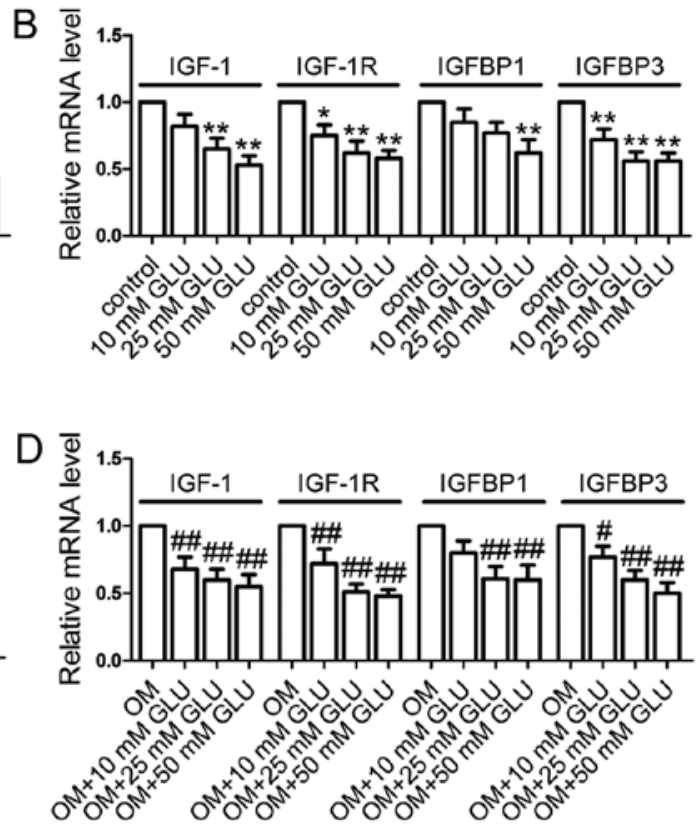

IGF-1R
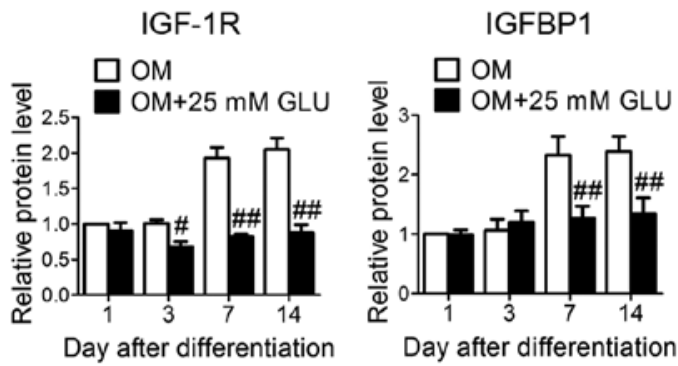

Day after differentiation
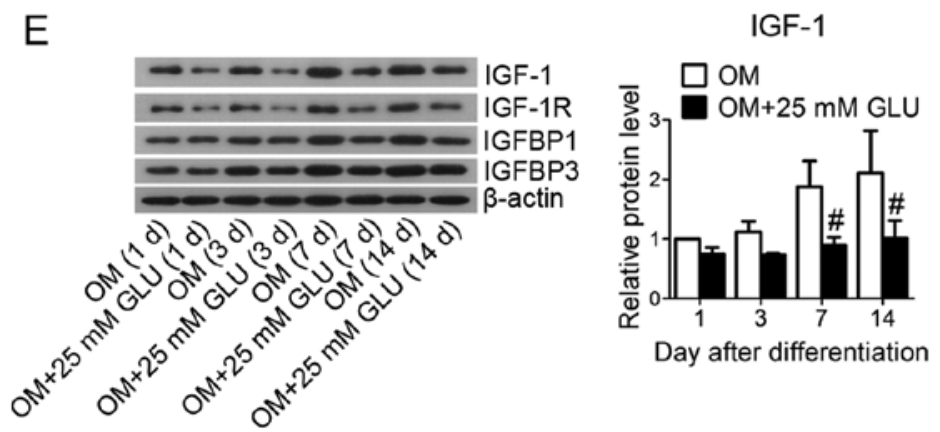

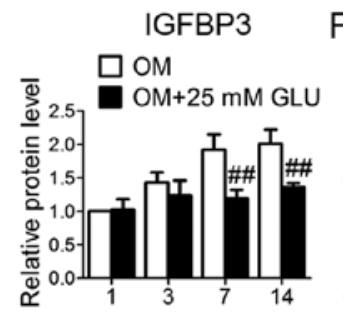

Day after differentiation

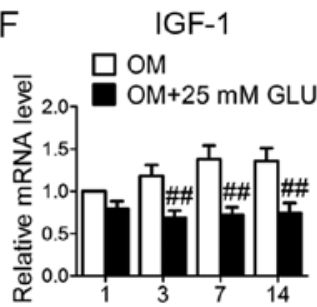

Day after differentiation

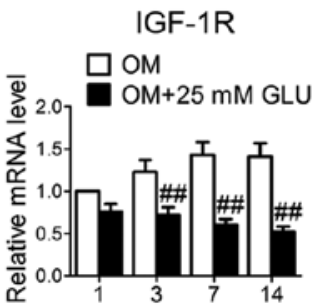

Day after differentiation

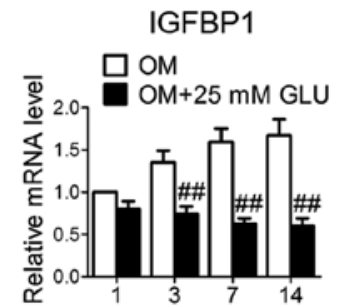

Day after differentiation

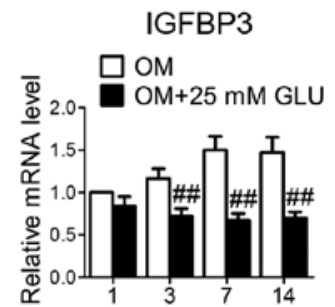

Day after differentiation

Figure 3. Effect of high glucose (GLU) on the expression levels of insulin-like growth factor-1 (IGF-1) family members. (A) Dental pulp cells (DPCs) were cultured in Dulbecco's modified Eagle's medium (DMEM) containing various concentrations of GLU (10, 25 and $50 \mathrm{mM}$ ) for $24 \mathrm{~h}$. Total proteins were extracted from the cells and the expression levels of IGF-1, IGF-1 receptor (IGF-1R), IGF-binding protein 1 (IGFBP1) and IGFBP3 were then measured by western blot analysis $\beta$-actin was used as a loading control. (B) The mRNA levels of IGF-1 family members were measured by RT-qPCR and normalized against the $\beta$-actin level (C) DPCs were cultured in odontoblastic induction medium (OM) containing various concentrations of GLU (10, 25 and $50 \mathrm{mM}$ ) for 7 days. The protein levels of IGF-1 family members were analyzed by western blot analysis. (D) RT-PCR analysis of IGF-1, IGF-1R, IGFBP1 and IGFBP3 mRNA levels. (E) Western blot analysis of the levels of IGF-1 family members on days 1, 3, 7 and 14 after differentiation. (F) RT-qPCR analysis of the levels of IGF-1 family members. ${ }^{\mathrm{P}}<0.05$ and ${ }^{* *} \mathrm{P}<0.01$ vs. control group; ${ }^{\#} \mathrm{P}<0.05$ and ${ }^{\# \#} \mathrm{P}<0.01$ vs. $\mathrm{OM}$ group.

It has been reported that hyperglycemia inhibits pulp repair (29). A previous study demonstrated that a high concentration of D-GLU $(30 \mathrm{mM})$ markedly inhibited the proliferation of MD10-F2 pulp cells compared with the controls in vitro (30). Furthermore, previous studies have also demonstrated that high GLU $(25 \mathrm{mM})$ reduces the proliferative capability of human cavernous endothelial cells (HCECs) and induces cell apoptosis in vitro $(31,32)$. Our experiments consistently demonstrated that high GLU, particularly at the concentrations of 25 and $50 \mathrm{mM}$, markedly suppressed human DPC proliferation and promoted cell apoptosis. ALP is a marker of odontoblastic differentiation and its activity is enhanced during odontoblastic induction $(33,34)$. We found that high GLU inhibited ALP activity and mineralization in DPCs, suggesting that high GLU inhibited the proliferation and differentiation and induced the apoptosis of DPCs.

IGF-1 is an ubiquitous peptide hormone and an important anti-apoptotic factor (35). IGFBPs constitute multiple proteins that bind to IGFs and modulate the interaction of IGFs with their receptors (36). Yu et al reported that high GLU leads to cardiomyocyte H9c2 cell apoptosis by decreasing IGF-1R 

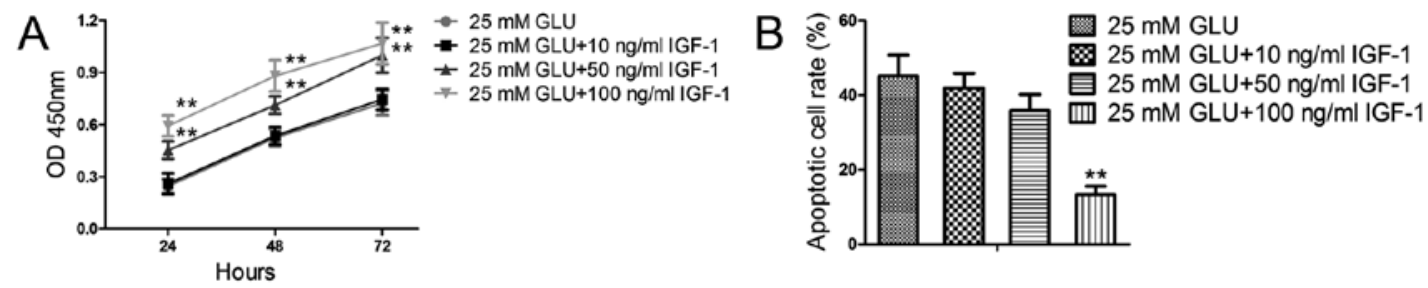

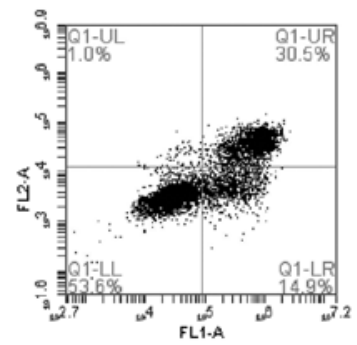

$25 \mathrm{mM}$ GLU

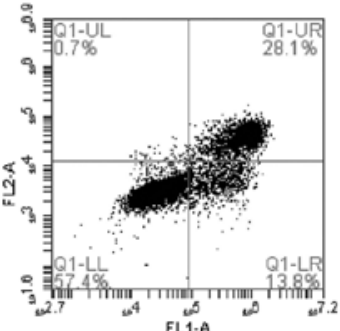

$25 \mathrm{mM} \mathrm{GLU}$

$+10 \mathrm{ng} / \mathrm{ml} \mathrm{IGF-1}$

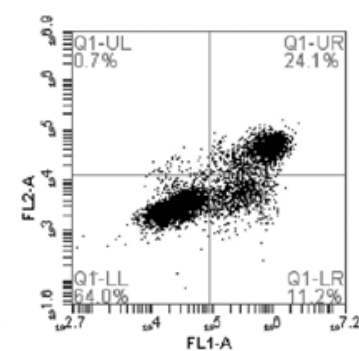

$25 \mathrm{mM}$ GLU

$+25 \mathrm{ng} / \mathrm{ml} \mathrm{IGF-1}$

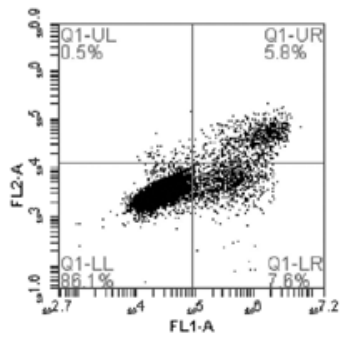

$25 \mathrm{mM}$ GLU

$+50 \mathrm{ng} / \mathrm{ml} \mathrm{IGF-1}$

Figure 4. Effect of insulin-like growth factor-1 (IGF-1) on the proliferation and apoptosis of human dental pulp cells (DPCs) under high glucose (GLU) conditions. (A) The cells were incubated with $25 \mathrm{mM}$ GLU and IGF-1 (10, 50 and $100 \mathrm{ng} / \mathrm{ml})$. Cell proliferation was evaluated by Cell Counting Kit- 8 (CCK-8) assay. (B) Apoptosis was analysis by Annexin V-FITC/propidium iodide (PI) staining assay. " P<0.01 vs. $25 \mathrm{mM}$ GLU group.

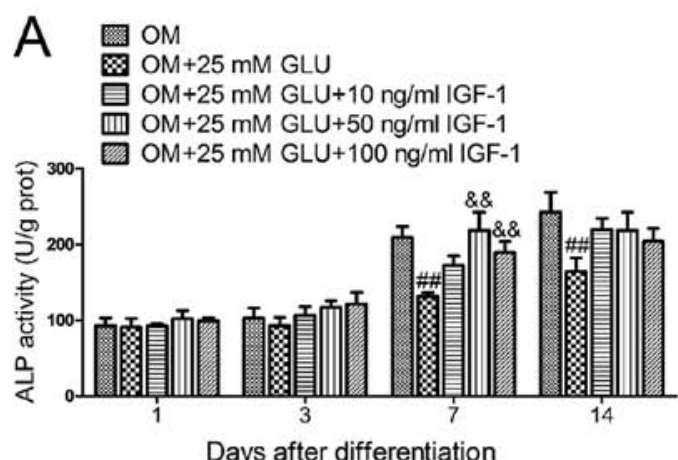

Days after differentiation

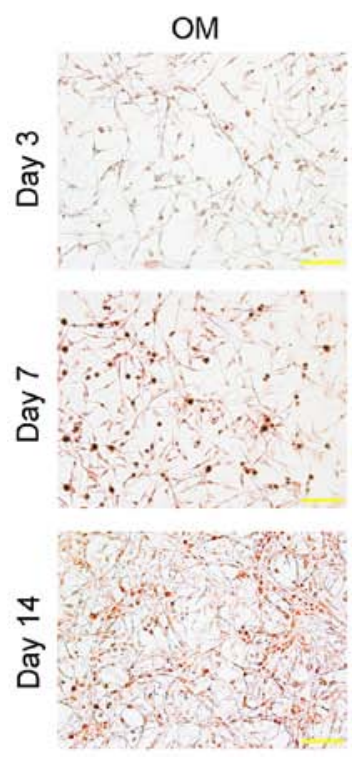
$\mathrm{OM}+25 \mathrm{mM}$ GLU

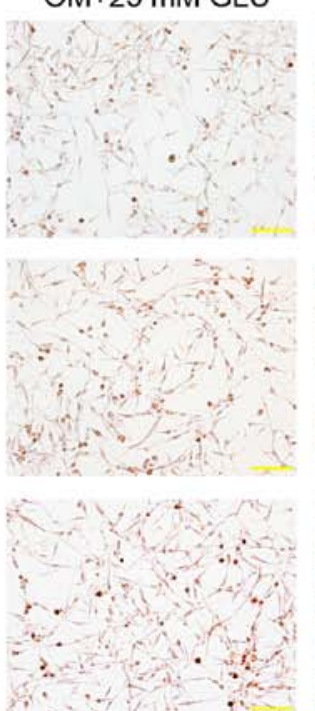

B

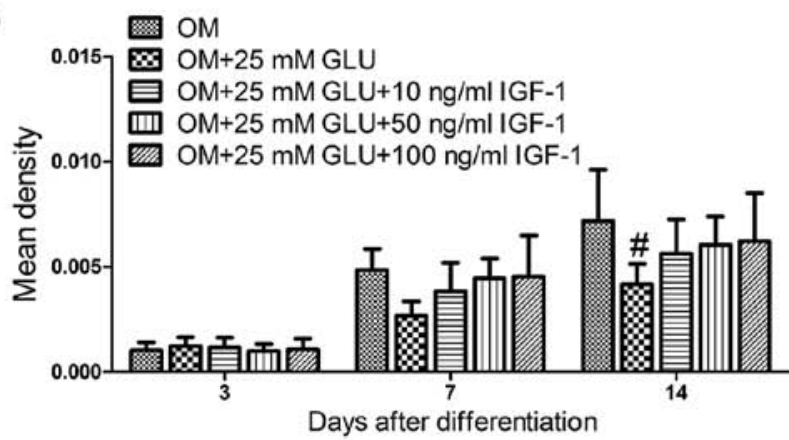

$\mathrm{OM}+25 \mathrm{mM} \mathrm{GLU}$
$+10 \mathrm{ng} / \mathrm{ml} \mathrm{IGF}-1$
$\mathrm{OM}+25 \mathrm{mM}$ GLU $+50 \mathrm{ng} / \mathrm{ml} \mathrm{IGF-1}$

Figure 5. Effect of insulin-like growth factor-1 (IGF-1) on the differentiation and mineralization of dental pulp cells (DPCs). (A) The cells cultured with odontoblastic induction medium (OM) were incubated with IGF-1 under high glucose (GLU) conditions. Alkaline phosphatase (ALP) activity was determined on days 1, 3, 7 and 14 after odontoblastic differentiation induction. (B) von Kossa staining of DPCs treated with high GLU (25 mM GLU) and IGF-1 in OM. Scale bar, $200 \mu \mathrm{m} .{ }^{\#} \mathrm{P}<0.05$ and ${ }^{\# \#} \mathrm{P}<0.01$ vs. OM group; ${ }^{\& \&} \mathrm{P}<0.01$ vs. OM+25 mM GLU group.

expression (37). Therefore, we hypothesized that high GLU would also affect the expression of IGF-1 family members in human DPCs that underwent apoptosis and differentiation. Our results revealed that 25 and $50 \mathrm{mM}$ GLU markedly decreased 

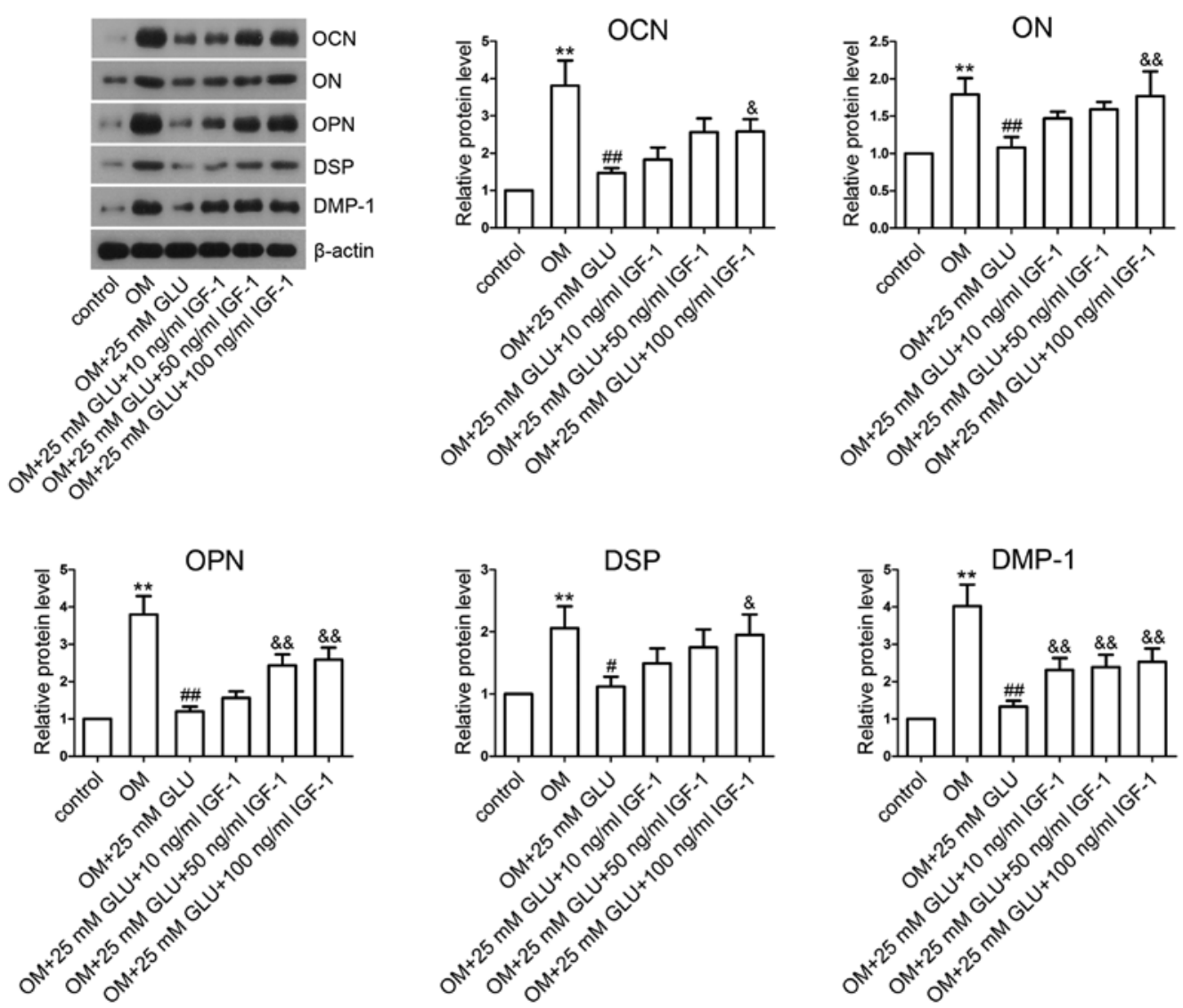

Figure 6. Effect of insulin-like growth factor-1 (IGF-1) on the expression of mineralization-related proteins under high glucose (GLU) conditions. The expression levels of mineralization-related proteins, including osteocalcin $(\mathrm{OCN})$, osteonectin $(\mathrm{ON})$, osteopontin (OPN), dentin sialoprotein (DSP) and dentin matrix protein-1 (DMP-1) were examined by western blot analysis 7 days after differentiation. ${ }^{* *} \mathrm{P}<0.01$ vs. control group; ${ }^{*} \mathrm{P}<0.05$ and ${ }^{\# \#} \mathrm{P}<0.01$ vs. odontoblastic induction medium $(\mathrm{OM})$ group; ${ }^{\&} \mathrm{P}<0.05$ and ${ }^{\& \&} \mathrm{P}<0.01$ vs. $\mathrm{OM}+25 \mathrm{mM}$ GLU group.

the expression levels of IGF-1, IGF-1R, IGFBP1 and IGFBP3 in DPCs that were cultured in normal DMEM for $24 \mathrm{~h}$ or in OM after 7 days of differentiation. Additionally, we found that $25 \mathrm{mM}$ GLU significantly decreased the IGF-1, IGF-1R, IGFBP1 and IGFBP3 levels from day 3 or 7 after differentiation.

IGF-1 binds to and activates the receptor IGF-1R and thus promotes cell proliferation and survival (38). Zhang et al reported that IGF-1 attenuated high fat diet-induced mitochondrial damage, myocardial contraction dysfunction and cardiomyocyte apoptosis (39). As expected, our results revealed that IGF-1 reversed the effects of high GLU on cell proliferation and protected the DPCs against apoptosis, suggesting the protective effects of IGF-1 in DPCs under conditions of high GLU.

It is well known that high GLU inhibits the osteoblast differentiation of MC3T3-E1 cells (40). IGF-1 has been demonstrated to promote the proliferation and differentiation of osteoblasts and chondrocytes in vitro (41). However, the effects of IGF-1 on the differentiation of human DPCs under high GLU conditions remain unknown. The process of odontoblastic differentiation involves multiple proteins (1). $\mathrm{OCN}$ is an important differentiation marker that is found in odontoblasts, dentine matrix and bone matrix. It is associated with mineralization and matrix deposition (42). ON is a major non-collagenous protein that is responsible for bone and dentin mineralization (43). OPN, a secreted glycophosphoprotein, is an odontoblastic marker for early differentiation (44). DSPP is a collagenous extracellular matrix (ECM) protein that partici- pates in dentin mineralization. It can be cleaved into DSP and dentin phosphoprotein (DPP) (45). DMP-1 is also correlated with dentin formation and mineralization (46). In our study, the differentiation of DPCs into odontoblastic cells was evaluated by measuring ALP activity, mineralization and the levels of mineralization-associated proteins (OCN, ON, OPN, DSP and DMP-1). We provide similar findings that $25 \mathrm{mM}$ GLU markedly suppressed the activity of ALP and decreased the mineralized matrix deposition in primary human DPCs that underwent differentiation. Furthermore, $25 \mathrm{mM}$ GLU significantly decreased OCN, ON, OPN, DSP and DMP-1 expression in DPCs during differentiation. These results indicate that high GLU inhibits the odontoblastic differentiation of DPCs. However, IGF-1 restored ALP activity and mineralization in the DPCs, suggesting that IGF-1 attenuates the effects of high GLU and promotes the odontoblastic differentiation of DPCs under high GLU conditions by increasing the expression levels of mineralization-related proteins.

In conclusion, the findings of the present study suggest that IGF-1 promotes the survival and odontoblastic differentiation of DPCs, and protects the cells against apoptosis in a high GLU environment.

\section{References}

1. Wang YL, Hu YJ and Zhang FH: Effects of GPNMB on proliferation and odontoblastic differentiation of human dental pulp cells. Int J Clin Exp Pathol 8: 6498-6504, 2015. 
2. Wu Q, Qi S, Ma J, Chen F, Chen J, Li J, Zhang X, Xu Y, Pan Q and Wang R: The Effect of NRAGE on cell cycle and apoptosis of human dental pulp cells and MDPC-23. Int J Clin Exp Med 8: $10657-10667,2015$.

3. Cooper PR, Takahashi Y, Graham LW, Simon S, Imazato S and Smith AJ: Inflammation-regeneration interplay in the dentine-pulp complex. J Dent 38: 687-697, 2010.

4. Jiang W, Lv H, Wang H, Wang D, Sun S, Jia Q, Wang P, Song B and Ni L: Activation of the NLRP3/caspase-1 inflammasome in human dental pulp tissue and human dental pulp fibroblasts. Cell Tissue Res 361: 541-555, 2015.

5. Han N, Zheng Y, Li R, Li X, Zhou M, Niu Y and Zhang Q: $\beta$-catenin enhances odontoblastic differentiation of dental pulp cells through activation of Runx2. PLoS One 9: e88890, 2014.

6. Saleh F, Ara F, Mumu SJ and Hafez MA: Assessment of health-related quality of life of Bangladeshi patients with type 2 diabetes using the EQ-5D: a cross-sectional study. BMC Res Notes 8: 497, 2015.

7. Stumvoll M, Goldstein BJ and van Haeften TW: Type 2 diabetes: principles of pathogenesis and therapy. Lancet 365 1333-1346, 2005.

8. Al Ghamdi AA, Badr G, Hozzein WN, Allam A, Al-Waili NS, Al-Wadaan MA and Garraud O: Oral supplementation of diabetic mice with propolis restores the proliferation capacity and chemotaxis of B and T lymphocytes towards CCL21 and CXCL12 by modulating the lipid profile, the pro-inflammatory cytokine levels and oxidative stress. BMC Immunol 16: 54, 2015.

9. Peng H, Li J, Chen X, Zhou X, Zhu W and Li F: Genetic variants of PTPN2 gene in chinese children with type 1 diabetes mellitus. Med Sci Monit 21: 2653-2658, 2015.

10. Ranasinghe $\mathrm{P}$, Pigera S, Galappatthy $\mathrm{P}$, Katulanda $\mathrm{P}$ and Constantine GR: Zinc and diabetes mellitus: understanding molecular mechanisms and clinical implications. Daru 23: 44, 2015

11. Shi Y and Hu FB: The global implications of diabetes and cancer. Lancet 383: 1947-1948, 2014.

12. Fung CS, Wan EY, Jiao F and Lam CL: Five-year change of clinical and complications profile of diabetic patients under primary care: a population-based longitudinal study on 127,977 diabetic patients. Diabetol Metab Syndr 7: 79, 2015.

13. Elabd S and Sabry I: Two birds with one stone: possible dual-role of oxytocin in the treatment of diabetes and osteoporosis. Front Endocrinol (Lausanne) 6: 121, 2015

14. Ferreira MM, Carrilho E and Carrilho F: Diabetes mellitus and its influence on the success of endodontic treatment: a retrospective clinical study. Acta Med Port 27: 15-22, 2014 (In Portuguese).

15. Madani ZS, Haddadi A, Mesgarani A, Seyedmajidi M, Mostafazadeh A, Bijani A and Ashraphpour M: Histopathologic responses of the dental pulp to calcium-enriched mixture (CEM) and mineral trioxide aggregate (MTA) in diabetic and non-diabetic rats. Int J Mol Cell Med 3: 263-271, 2014.

16. Claudino M, Nunes IS, Gennaro G, Cestari TM, Spadella CT, Garlet GP and de Assis GF: Diabetes triggers the loss of tooth structure associated to radiographical and histological dental changes and its evolution to progressive pulp and periapical lesions in rats. Arch Oral Biol 60: 1690-1698, 2015.

17. Catanzaro O, Dziubecki D, Lauria LC, Ceron CM and Rodriguez RR: Diabetes and its effects on dental pulp. J Oral Sci 48: 195-199, 2006

18. Amatyakul S, Chakraphan D, Chotpaibulpan S and Patumraj S: The effect of long-term supplementation of vitamin $\mathrm{C}$ on pulpal blood flow in streptozotocin-induced diabetic rats. Clin Hemorheol Microcirc 29: 313-319, 2003.

19. Garber SE, Shabahang S, Escher AP and Torabinejad M: The effect of hyperglycemia on pulpal healing in rats. J Endod 35: 60-62, 2009

20. Wolfe A, Divall S and Wu S: The regulation of reproductive neuroendocrine function by insulin and insulin-like growth factor-1 (IGF-1). Front Neuroendocrinol 35: 558-572, 2014.

21. Limesand $\mathrm{KH}$, Chibly AM and Fribley A: Impact of targeting insulin-like growth factor signaling in head and neck cancers. Growth Horm IGF Res 23: 135-140, 2013

22. Catón J, Bringas P Jr and Zeichner-David M: IGFs increase enamel formation by inducing expression of enamel mineralizing specific genes. Arch Oral Biol 50: 123-129, 2005.

23. Joseph BK, Savage NW, Young WG, Gupta GS, Breier BH and Waters MJ: Expression and regulation of insulin-like growth factor-I in the rat incisor. Growth Factors 8: 267-275, 1993.

24. Feng X, Huang D, Lu X, Feng G, Xing J, Lu J, Xu K, Xia W, Meng Y, Tao T, et al: Insulin-like growth factor 1 can promote proliferation and osteogenic differentiation of human dental pulp stem cells via mTOR pathway. Dev Growth Differ 56: 615-624, 2014
25. Pauly K,Fritz K,Furey A and Lobner D: Insulin-like growth factor 1 and transforming growth factor- $\beta$ stimulate cystine/glutamate exchange activity in dental pulp cells. J Endod 37: 943-947, 2011.

26. Livak KJ and Schmittgen TD: Analysis of relative gene expression data using real-time quantitative PCR and the 2(-Delta Delta C(T)) Method. Methods 25: 402-408, 2001.

27. Woo SM, Lim HS, Jeong KY, Kim SM, Kim WJ and Jung JY: Vitamin D promotes odontogenic differentiation of human dental pulp cells via ERK activation. Mol Cells 38: 604-609, 2015.

28. Välikangas L, Pekkala E, Larmas M, Risteli J, Salo T and Tjäderhane L: The effects of high levels of glucose and insulin on type I collagen synthesis in mature human odontoblasts and pulp tissue in vitro. Adv Dent Res 15: 72-75, 2001.

29. Ryan ME, Carnu O and Kamer A: The influence of diabetes on the periodontal tissues. J Am Dent Assoc 134: 34S-40S, 2003.

30. Yeh CK, Harris SE, Mohan S, Horn D, Fajardo R, Chun YH, Jorgensen J, Macdougall M and Abboud-Werner S: Hyperglycemia and xerostomia are key determinants of tooth decay in type 1 diabetic mice. Lab Invest 92: 868-882, 2012.

31. Li H, Xu Y, Guan R, Matheu M, Lei H, Tian W, Gao Z, Lin G, Guo Y, Xin Z, et al: Icariside II prevents high-glucose-induced injury on human cavernous endothelial cells through Akt-eNOS signaling pathway. Andrology 3: 408-416, 2015.

32. Ning H, Qiu X, Baine L, Lin G, Lue TF and Lin CS: Effects of high glucose on human cavernous endothelial cells. Urology 80: 1162.e7-e11, 2012.

33. Qi S, Wu Q, Ma J, Li J, Chen F, Xu Y, Pan Q and Wang R: Effects of neurotrophin receptor-mediated MAGE homology on proliferation and odontoblastic differentiation of mouse dental pulp cells. Cell Prolif 48: 221-230, 2015.

34. Lee DH, Lim BS, Lee YK and Yang HC: Effects of hydrogen peroxide $\left(\mathrm{H}_{2} \mathrm{O}_{2}\right)$ on alkaline phosphatase activity and matrix mineralization of odontoblast and osteoblast cell lines. Cell Biol Toxicol 22: 39-46, 2006.

35. Zhang GW, Gu TX, Guan XY, Sun XJ, Qi X, Li XY, Wang XB, Lv F, Yu L, Jiang DQ, et al: HGF and IGF-1 promote protective effects of allogeneic BMSC transplantation in rabbit model of acute myocardial infarction. Cell Prolif 48: 661-670, 2015.

36. Song SE, Kim YW, Kim JY, Lee DH, Kim JR and Park SY: IGFBP5 mediates high glucose-induced cardiac fibroblast activation. J Mol Endocrinol 50: 291-303, 2013.

37. Yu XY, Geng YJ, Liang JL, Lin QX, Lin SG, Zhang S and Li Y: High levels of glucose induce apoptosis in cardiomyocyte via epigenetic regulation of the insulin-like growth factor receptor. Exp Cell Res 316: 2903-2909, 2010.

38. Chen C, Xu Y and Song Y: IGF-1 gene-modified muscle-derived stem cells are resistant to oxidative stress via enhanced activation of IGF-1R/PI3K/AKT signaling and secretion of VEGF. Mol Cell Biochem 386: 167-175, 2014.

39. Zhang Y, Yuan M, Bradley KM, Dong F, Anversa P and Ren J: Insulin-like growth factor 1 alleviates high-fat diet-induced myocardial contractile dysfunction: role of insulin signaling and mitochondrial function. Hypertension 59: 680-693, 2012.

40. You L, Gu W, Chen L, Pan L, Chen J and Peng Y: miR-378 overexpression attenuates high glucose-suppressed osteogenic differentiation through targeting CASP3 and activating PI3K/Akt signaling pathway. Int J Clin Exp Pathol 7: 7249-7261, 2014.

41. Onishi T, Kinoshita S, Shintani S, Sobue S and Ooshima T: Stimulation of proliferation and differentiation of $\operatorname{dog}$ dental pulp cells in serum-free culture medium by insulin-like growth factor. Arch Oral Biol 44: 361-371, 1999.

42. Ito K, Matsuoka K, Matsuzaka K, Morinaga K and Inoue T: Hypoxic condition promotes differentiation and mineralization of dental pulp cells in vivo. Int Endod J 48: 115-123, 2015.

43. Karanxha L, Park SJ, Son WJ, Nör JE and Min KS: Combined effects of simvastatin and enamel matrix derivative on odontoblastic differentiation of human dental pulp cells. J Endod 39: 76-82, 2013.

44. Liu M, Wang Q, Tang R, Cao R and Wang X: Nel-like molecule 1 contributes to the odontoblastic differentiation of human dental pulp cells. J Endod 42: 95-100, 2016

45. Paula-Silva FW, Ghosh A, Silva LA and Kapila YL: TNF-alpha promotes an odontoblastic phenotype in dental pulp cells. J Dent Res 88: 339-344, 2009.

46. Qi SC, Cui C, Yan YH, Sun GH and Zhu SR: Effects of high-mobility group box 1 on the proliferation and odontoblastic differentiation of human dental pulp cells. Int Endod J 46: 1153-1163, 2013. 